\title{
BONDADE, SUBSTANTIVO FEMININO: ESBOÇO PARA UMA HISTÓRIA DA BENEVOLÊNCIA E DA FEMINILIZAÇÃO DA BONDADE
}

\author{
Goodness, a feminine noun: an outline for a history of \\ benevolence and the feminization of goodness
}

Ana Paula Vosne Martins*

\begin{abstract}
RESUMO
Este artigo trata do processo de feminilização das ações de socorro, proteção e assistência aos pobres e a outras categorias de pessoas em situação de fragilidade, desamparo e abandono. A organização dos cuidados com os chamados desafortunados tem sido historicamente uma ação dispensada pelos poderosos, associada à sua capacidade de prover e de socorrer aqueles que batiam às suas portas pedindo abrigo temporário, víveres ou remédios para seus males, ou então aos religiosos, de quem se esperava a caridade para com os sofredores de toda espécie. Numa visão de mundo profundamente marcada pela religião cristã, o gênero não hierarquizava nem a dádiva, nem a caridade, associadas ao poder e ao prestígio das famílias e da religião, operando e adquirindo sentido no interior de uma lógica simbólica do sangue, das famílias e da esfera do sagrado. A bondade, portanto, adquiria sentido e significado numa ordem hierárquica mais estável e intimamente relacionada às capacidades distributivas do poder patriarcal e religioso. $\mathrm{O}$ gênero passou a desempenhar um papel importante nesta economia da dádiva quando os cuidados e o conjunto de ações e de significados a eles associados foram ressignificados por novos discursos na modernidade, fundados numa reorganização dos espaços, dos sujeitos, das práticas sociais e dos valores e comportamentos. Desde meados do século XVIII e especialmente a partir do século XIX, observa-se a configuração de
\end{abstract}

* Professora Associada do Departamento de História e do Programa de Pós-Graduação em História da Universidade Federal do Paraná. Este artigo é resultado de pesquisa financiada pelo CNPq (Bolsista de Produtividade) e pela Fundação Araucária (Projeto Sentimentos na História, do Edital de Apoio a Projetos de Pesquisa dos Programas de Pós-Graduação Notas 5 e 6). 
espaços, de práticas e de sentimentos definidores de subjetividades consideradas femininas, associadas ao amplo terreno moral dos cuidados. Tal processo de generificação dos cuidados se articula ao afastamento e posterior exclusão das mulheres dos espaços públicos, processo este que se configura nas sociedades ocidentais modernas. As mulheres das elites e das classes médias passaram a ser associadas às virtudes regeneradoras da ordem moral e social e a uma concepção natural de bondade, altruísmo e dedicação aos necessitados, valores presentes tanto nas ações de motivação caritativa quanto na organização racionalizada da filantropia, na definição e implementação das políticas assistenciais e na organização das profissões femininas criadas a partir da experiência heterogênea dos cuidados.

Palavras-chave: sentimentos; cuidados; gênero; filantropia.

\begin{abstract}
This article deals with the process of feminization of relief, protection and assistance actions to the poor and to other categories of people in situations of fragility, helplessness and abandonment. The organization of the care of the so called unfortunate has historically been an action given by the powerful, associated with their ability to provide and to assist those knocking at their doors asking for temporary shelter, food or medicines for their ailments, or by religious, from whom charity for sufferers of all kinds was expected. In a deeply marked by the Christian religion worldview, the gender did not prioritize gift nor charity, associated with the power and prestige of the families and religion, operating and acquiring sense within a symbolic logic of the blood, of the families and the sacred sphere. The goodness therefore acquired sense and meaning in a hierarchical order more stable and closely related to the distributive capabilities of patriarchal and religious power. The gender went on to play an important role in this economy of the gift when the care and the set of actions and of meanings associated with them were redefined by new discourses in modernity, founded on a reorganization of the spaces, subjects, social practices and values and behaviors. Since the mid-18th century and especially from the 19th century on there is a configuration of spaces, practices and subjectivities defining feelings considered feminine, associated with the broad moral field of care. Such gendering process of care articulates the removal and subsequent exclusion of women from public spaces, this process represented in modern Western societies. The elite and middle class women began to be associated with the regenerative virtues of moral and social order and with a natural conception of goodness, unselfishness and dedication to those in need, values present in the charitable motivation actions, in
\end{abstract}


rationalized organization of philanthropy, in the definition and implementation of assistance policies and in the organization of professions for women created from the heterogeneous care experience.

Keywords: feelings; care; gender; philanthropy.

As palavras e os sentimentos têm história, como sabemos, e alguns deles parecem entrar em zonas de esquecimento ou de desuso, como é o caso da palavra bondade. Em nosso tempo, esta palavra raramente é usada para definir as qualidades de alguém que se envolva com ações de benemerência. Pessoas podem ser solidárias, engajadas ou comprometidas com os outros ou com comunidades que por inúmeras razões sofrem, são injustiçadas e precisam de ajuda, mas raramente nos referimos a este tipo de ação como sendo exemplo de bondade. Afinal, os bons podem parecer ingênuos, pessoas facilmente enganadas por causa da sua bondade; bons podem ser pessoas excepcionais, como religiosas e religiosos devotados aos pobres, a exemplo de Irmã Dulce ou tantas outras que mais parecem fazer parte de outro mundo, o mundo dos beatos e dos santos, do que do nosso mundo real.

Bondade é uma palavra meio fora de moda nos nossos dias, talvez porque pertença historicamente a um léxico moral e religioso e atualmente as ações humanitárias e filantrópicas estejam cada vez mais vinculadas a outros códigos, não necessariamente distantes da motivação religiosa, mas que reforçam as responsabilidades individuais e/ou coletivas e concepções mais racionalizadas e pretensamente neutras de atitude ética e humanitária. Muitas outras qualidades éticas podem ser invocadas em situações críticas ou de risco à segurança e à dignidade humana, mas dificilmente a bondade seja uma delas, embora no plano das emoções consideremos as ações humanitárias como exemplos de bondade. Mas, o que vem a ser bondade?

Nos textos filosóficos e religiosos antigos, lemos que a bondade é a disposição para fazer o bem e este é um fim último, ponto de partida da criação e da existência, atributo divino, aquilo que nós, mortais e pecadores, almejamos no reencontro com o plano divino. Bondade, portanto, é ação virtuosa, requer disposição moral para afastar-se de si e dos interesses próprios imediatos com a finalidade de fazer o bem a alguém que esteja necessitado de algo, material ou imaterial, sem esperar retribuição, numa demonstração de elevação moral e espiritual. Do ponto de vista ético ou religioso, a bon- 
dade é uma qualidade ou uma virtude que requer vontade, escolha e ação. $\mathrm{O}$ homem ou a mulher bons não o são sem a escolha motivada pela razão ou pelo sentimento, nem sem a ação benevolente. Trata-se, portanto, de uma virtude que necessariamente requer ação em relação ao outro, mas também uma distinção, afinal ser bom não é decorrência da natureza humana, como bem sabiam os filósofos antigos e os profetas. Nem todos são bons porque nem todos podem ou querem ser bons e essa é uma linha de argumentação à qual vamos retornar ao longo do artigo.

Com o passar do tempo, especialmente na Modernidade, a definição de bondade vai lentamente deixando o abrangente terreno da racionalidade ética para adentrar no terreno mais restrito das emoções ou dos sentimentos morais. A ênfase crescente na capacidade natural dos seres humanos em fazer o bem, em sentir piedade e compaixão com os sofredores e necessitados é resultado de um conjunto de mudanças contemporâneas nos processos macro-históricos da expansão cultural e política europeia, do capitalismo e do colonialismo, das quais destacamos as sensibilidades mais aguçadas com o sofrimento; as experiências religiosas decorrentes da Reforma Protestante e da Reforma Católica, com seus apelos renovados à espiritualidade cristã e às manifestações exteriores da caridade; as modernas concepções filosóficas sobre a natureza humana; e novas configurações históricas das subjetividades fortemente ancoradas no gênero, na raça e na classe social.

A história de um sentimento como a bondade pode nos levar para diferentes dimensões da experiência e do pensamento modernos, algo que certamente extrapola as limitações deste artigo. Vamos nos ater a uma destas dimensões, a das subjetividades, nem mais nem menos importante do que as outras, mas cuja relevância defendemos por estar atrelada às mudanças sociais, culturais e econômicas consideráveis, particularmente entre os séculos XVIII e XIX. Os diferentes discursos modernos produzidos em torno da questão fundamental do Sujeito não são neutros do ponto de vista político e ideológico, como bem compreenderam alguns homens e as mulheres que enveredaram pela cultura escrita e pelo pensamento crítico na modernidade. As qualidades do sujeito e seus direitos naturais e políticos não eram extensivos, permanecendo na sombra da cidadania as mulheres, os escravos, os pobres e todos aqueles que estavam fora do círculo restrito da civilização europeia. O Sujeito tinha, portanto, marcas muito bem definidas da masculinidade, dos privilégios de classe e de raça. 
No lento e descontínuo processo de configuração das subjetividades modernas, o gênero é uma categoria central, solidamente incorporado, sexuado e institucionalizado. Os discursos de gênero estão nas origens da separação e da delimitação de espaços, de valores e de práticas que são naturalizadas, operando numa lógica binária muito presente na modernidade e nas suas múltiplas narrativas.

Os sentimentos e as virtudes são também ressignificados pelo gênero. A filosofia e a medicina modernas, em proximidade com algumas correntes religiosas e novas experiências estéticas, como o romantismo, sustentam que os sentimentos morais são naturais; portanto, a princípio todos seriam dotados de atributos morais como a bondade e a piedade. No entanto, o mesmo discurso naturalista também estabeleceu que a aproximação com a Natureza seria um indicativo do lugar ocupado pelos indivíduos na escala do aperfeiçoamento humano. Quanto mais próximo da Natureza, como os selvagens dos lugares distantes da civilização, os indivíduos rústicos das classes subalternas e as mulheres, mais distantes da perfeição. A ambiguidade é a marca desses discursos, como veremos mais à frente, pois os mesmos rústicos insensíveis e passionais poderiam ser considerados indivíduos capazes de atos de extrema bondade e piedade porque menos racionais. Nessa mesma direção, as mulheres ocupam um lugar cada vez mais importante nos discursos naturalistas. Seres mais sensíveis devido à maternidade, as mulheres seriam também mais dotadas de sentimentos morais, especialmente aqueles relacionados à piedade e aos cuidados com os mais fracos e miseráveis.

De virtude moral de ampla abrangência, a bondade foi aos poucos se tornando um atributo da natureza feminina, embora não se possa esquecer que muitos homens se notabilizaram pela bondade demonstrada com os mais diferentes tipos de pessoas e mesmo com os animais, praticando o amor à humanidade, representada pela palavra de uso cada vez mais corrente desde meados do século XVIII, a filantropia. Nesse artigo, vamos tratar do processo de feminilização da bondade, da associação entre a virtude benevolente e a feminilidade, processo este que está na origem de um duplo movimento na construção das subjetividades femininas modernas: de um lado, a reclusão ao privado e ao mundo dos sentimentos; de outro, a abertura para sair e participar do mundo público pela prática da benevolência. Caminhos de conformismo, de adequação e de dominação de classe, mas 
também caminhos para a autonomia, a participação social e o envolvimento com a política e o feminismo.

\section{As virtudes morais e o poder de fazer o bem}

Falar sobre a bondade nos remete ao terreno da ética e da moral. A bondade foi definida como uma virtude moral, portanto, uma qualidade aprendida e cultivada pelos indivíduos dotados de razão, capazes de fazer boas escolhas, ou as mais corretas na forma de conduzir suas vidas. Recorrendo a um texto seminal para a cultura ocidental, a Ética, de Aristóteles, mas também a alguns dos diálogos platônicos, em especial Menon e $A R e-$ pública, encontramos a elaboração de um pensamento complexo e de grande importância prática sobre a finalidade da vida e a melhor forma de viver, questão central para o pensamento filosófico pagão e, posteriormente, para o pensamento cristão. Aristóteles explicava ser tarefa da ética tratar desta questão (a melhor vida), descrevendo a natureza da felicidade e explicando os meios para obtê-la.

O conceito usado por Aristóteles para significar a felicidade como sendo o bem supremo é eudaimonia, que denota um estado ativo de bem-estar e de bem fazer. Assim, a eudaimonia seria um objetivo completo e suficiente por si mesmo. ${ }^{1}$ Seguindo a construção argumentativa de Aristóteles, a eudaimonia é um estado que se alcança pelo caminho da razão. Almejar a vida boa requer escolhas conduzidas pela sabedoria, portanto, a vida boa é aquela vivida com virtude, outra palavra-chave no léxico ético aristotélico e de longeva sobrevivência no Ocidente.

De maneira simplificada, virtude significa caminho, ou o melhor caminho em nossas escolhas. No prefácio escrito por Crayling à edição da Folio Society de 2003, encontramos exemplos sobre as escolhas virtuosas: a coragem é o caminho entre a covardia e a imprudência; a generosidade é o caminho entre a avareza e o desregramento. Portanto, um indivíduo de virtudes é aquele que sabe escolher, tem as melhores atitudes na condução

1 CRAYLING, A. C. Preface. In: ARISTOTELES. Ethics. Trad. J. A. K. Thomson. London: The Folio Society, 2003. 
da sua vida e, ao demonstrar tal sabedoria prática, é digno de elogios, de reconhecimento e de memória. ${ }^{2}$

Na Ética, as virtudes são classificadas em dois grupos: virtudes intelectuais, como a sabedoria, a prudência e o conhecimento; e virtudes morais, como a coragem, a liberalidade, a temperança, a magnificência e a justiça. Destas, vamos nos deter na liberalidade, por tratar das relações de troca e do ato de dar, tema frequentemente abordado nos tratados sobre ética no que diz respeito às ações benevolentes.

Liberalidade é a atitude correta em relação às coisas materiais, especialmente em relação ao dinheiro. Segundo Aristóteles, um homem liberal é aquele que sabe dar suas posses, suas ações são mais voltadas a esta razão do que a receber, afinal, a virtude da liberalidade implica demonstrar uma qualidade que somente alguns homens podem ter, ou seja, a grandeza, a magnanimidade. Homens possuidores dessa virtude certamente são homens de posses, se não ricos, bem situados quanto à sua posição social, à posse de bens e de escravos. A liberalidade é uma virtude enaltecida porque implica a inserção daquele que a pratica nas relações sociais. Talvez seja, junto com a justiça, a virtude social por excelência, afinal, aquele que dá tem o poder de fazer o bem a alguém que dele necessita, reforçando os laços sociais e as relações de reciprocidade. No entanto, a noção de medida, tão cara à sociedade e à cultura grega, deve prevalecer no gesto de dar. Aristóteles lembra que o homem liberal deve saber quando, quanto e a quem dar, caso contrário pode incorrer na prodigalidade e esta, se não for contida pela razão e pelo autocontrole, pode levar o homem liberal à exaustão de suas posses e riquezas. ${ }^{3}$

É importante destacar duas questões presentes no Livro IV da Ética. A primeira delas é a relação estabelecida entre o gesto de dar e fazer o bem. Para os gregos, um homem rico ou bem situado tinha o dever de fazer o bem para aqueles que se encontrassem em situação de penúria e de desamparo, fossem eles gregos ou estrangeiros. Dar dinheiro, abrigar,

2 Encontramos semelhante formulação na discussão proposta por Michel Foucault a respeito da problematização moral dos desejos para os gregos. A questão dos aphrodisia levou a uma ética sexual visando ao aperfeiçoamento, à sabedoria e à beleza. $\mathrm{O}$ indivíduo que demonstrasse em sua vida ter domínio sobre seus desejos e conduzir-se pela sabedoria e por um estilo de vida pautado pela moderação e pelo autocontrole seria digno de louvor, como Sócrates, e a ter sua memória preservada. FOUCAULT, Michel. História da sexualidade. O uso dos prazeres. Rio de Janeiro: Graal, 1998.

3 ARISTOTELES. Ethics. Trad. J. A. K. Thomson. London: The Folio Society, 2003. Livro IV, p. 69. 
fornecer víveres, entre outras ações, compunham gestos benevolentes que indicavam a qualidade do homem que os praticava, sua distinção moral e seu poder social, afinal, eram cidadãos honrados, bem situados e ricos. Portanto, a dádiva operava tanto no sentido de atender o imperativo moral de fazer o bem quanto no sentido de fortalecer o poder, a autoridade, o reconhecimento e a glória dos cidadãos magnânimos. Um desdobramento dessa primeira questão é bastante importante: nem todos podem praticar o bem, ou seja, mesmo que as virtudes sejam adquiridas pelo conhecimento e pela razão, são poucos aqueles capazes de se aperfeiçoar e se empoderar a tal ponto de ser um cidadão de virtudes. No caso da liberalidade, uma condição necessária é que seja alguém de posses, o que, do ponto de vista social, seja entre os gregos da época clássica, seja nas sociedades contemporâneas, restringe bastante as possibilidades.

A restrição social para a prática de ações benevolentes ou de outras expressões das virtudes intelectuais e morais nos leva para a segunda questão que pode ser depreendida do Livro IV da Ética. Trata-se da discussão sobre a influência ou não das diferenças sexuais na aquisição das virtudes. $\mathrm{Na}$ Ética, o sujeito das ações virtuosas ou o sujeito ético é o homem, o cidadão, portanto, há um discurso de gênero neste livro. No entanto, não há qualquer menção à incapacidade das mulheres para a aquisição da excelência moral, mas não se pode perder de vista aquelas considerações que fizemos em torno das restrições para o aperfeiçoamento moral e também lembrar que em outros de seus escritos Aristóteles foi um dos pensadores gregos mais deterministas no que diz respeito às diferenças entre homens e mulheres e à capacidade reduzida do sexo feminino devido a uma inferioridade natural. ${ }^{4}$

A dicotomia conceitual solidamente presente no pensamento aristotélico e nos autores subsequentes da cultura latina e cristã estabelece que todas as relações se constituem a partir de uma diferença. Essas relações não são apenas estabelecidas por uma diferença natural ou material, mas de qualidade, o que significa que um dos termos da relação estará em desvantagem quanto ao outro, criando uma relação de dominação do melhor, do mais forte, do mais justo com o inferior.

4 Refiro-me particularmente a duas obras de Aristóteles que reforçam esse primado naturalista na distinção e na hierarquia entre animais e humanos e entre os seres humanos: História dos animais e Politica. 
Es preciso, repito, reconocer ante todo en el ser vivo la existencia de una autoridad semejante a la vez a la de un señor y a la de un magistrado; el alma manda al cuerpo como un dueño a su esclavo, y la razón manda al instinto como un magistrado, como un Rey; porque, evidentemente, no puede negarse que no sea natural y bueno para el cuerpo el obedecer al alma, y para la parte sensible de nuestro ser el obedecer a la razón y a la parte inteligente. La igualdad o la dislocación del poder, que se muestra entre estos diversos elementos, sería igualmente funesta para todos ellos. Lo mismo se sucede entre los hombres e los demás animales: los animales domesticados valen naturalmente más que los animales salvajes, siendo para ellos una gran ventaja, si se considera su propia seguridad, el estar sometidos al hombre. Por otra parte, la relación de los sexos es análoga; el uno es superior al otro; éste está hecho para mandar, aquel para obedecer. ${ }^{5}$

No que diz respeito à aquisição das virtudes, Aristóteles diz no Capítulo V, a respeito do poder doméstico, que aquele que manda e aqueles que obedecem devem todos ter virtudes, só que estas são diferentes, obedecendo a natureza de cada um:

Evidentemente es necesario que ambos tengan virtudes, pero virtudes tan diversas como lo son las especies de seres destinados por la naturaleza a la sumisión. Esto mismo es lo que hemos dicho ya al tratar del alma. La naturaleza ha creado en ella dos partes distintas: la una destinada a mandar, la otra a obedecer, siendo sus cualidades bien diversas, pues que la una está dotada de razón y privada de ella la otra. Esta relación se extiende evidentemente a los otros seres, y respecto de los más de ellos la naturaleza ha establecido el mando y la obediencia. Así, el hombre libre manda al esclavo de muy distinta manera que el marido manda a la mujer y que el padre al hijo. [...] Lo mismo sucede necesariamente respecto a las virtudes morales. Se las debe suponer existentes en todos los seres, pero en grados diferentes, y solo en la proporción indispensable para el cumplimiento del destino de cada uno de ellos. El ser que manda debe poseer la virtud moral en toda su perfección. Su

5 ARISTÓTELES. Politica. Disponível em: <www.dominiopublico.gov.br $>$. Livro Primeiro, Capítulo 2, p. 13. 
tarea es absolutamente igual a la del arquitecto que ordena, y el arquitecto en este caso es la razón. En cuanto a los demás, deben estar adornados de las virtudes que reclamen las funciones que tienen que llenar. [...] Y así, en resumen, lo que dice el poeta de una das cualidades de la mujer: Un modesto silencio hace honor a la mujer es igualmente exacto respecto a todas las demás; reserva aquella que no sentaría bien en el hombre. ${ }^{6}$

As virtudes, portanto, são extensivas a todos os seres humanos porque são seres racionais, mas, segundo Aristóteles, elas são ajustadas à natureza e à qualidade de cada um, condição necessária para que todos desempenhem suas funções de maneira adequada à ordem natural e política. O gênero é uma categoria importante e destacada no texto aristotélico, a começar pelo exemplo emprestado de Sófocles, o poeta citado, a respeito de uma mulher de virtude.

A discussão em torno das virtudes masculinas e femininas não se apresentava da mesma maneira nos diálogos platônicos, especialmente Menon e A República, contrariamente aos quais se colocava Aristóteles na mesma passagem supracitada. Nestes diálogos, Sócrates defendia a doutrina da unidade da virtude, ou seja, se uma pessoa possuía uma virtude moral, ela possuía todas as outras virtudes morais. A defesa da doutrina da unidade da virtude se sustenta na racionalidade. Um indivíduo racional e sábio só poderia ser excelente, não admitindo Sócrates a ideia de escalas ou de ajustes para a aquisição das virtudes. Nesse sentido, a excelência moral não conheceria a distinção de gênero, pois todas as qualidades propiciadas pelas virtudes poderiam ser extensivas aos melhores homens e às melhores mulheres.

Seguindo a interpretação de Patrícia Ward, para Sócrates a virtude era conhecimento e cada parte do conhecimento moral era holisticamente dependente do restante, portanto, o conhecimento do bem requeria dos indivíduos de excelência a conduta mais correta em relação ao tratamento dispensado aos outros, frente aos perigos e aos deuses, evitando sempre o descontrole e a falta de medida. Se a pessoa tinha um desses conhecimentos, possuía o conhecimento do bem. ${ }^{7}$ Portanto, na formulação socrático-

6 ARISTÓTELES. Política. Disponível em: <www.dominiopublico.gov.br $>$. Livro Primeiro, Capítulo 5, p. 19 e 20.

7 WARD, Patricia. Virtue without gender in Socrates. Hypatia, v. 7, n. 3, Summer 1992. 
-platônica homens e mulheres não diferiam no que diz respeito à aquisição de virtudes, podendo as mulheres assumirem as mesmas funções decorrentes da excelência moral e não somente se restringir ao modesto silêncio da submissão.

Entretanto, não foi a teoria socrática que prevaleceu na história dos tratados de ética, mas as concepções aristotélicas da modulação das virtudes segundo a condição social e segundo o gênero. Na longa duração, observa-se que a problematização moral em relação à liberalidade dos grandes príncipes e senhores não se distinguia do poder militar, nem da classe, nem do poderio econômico. Tanto nos tratados éticos quanto no plano das expectativas sociais, se esperava dos poderosos que agissem com liberalidade em relação à religião e aos necessitados. Homens da guerra e de impérios deviam dar parte de suas riquezas porque a dádiva era uma das facetas de outro poder, não menos importante que o militar ou o poder econômico, o poder simbólico.

Marcel Mauss, em estudo que se tornou clássico sobre a dádiva, compreendeu, a partir de diferentes sociedades e culturas, que a vida social é um constante movimento entre dar e receber, implicando trocas materiais certamente, mas também gestos, palavras, emoções, deferências, reconhecimento. ${ }^{8}$ A dádiva enfeixa múltiplos significados e dimensões da vida social, aproximando aqueles que dão (ou que podem dar) e aqueles que recebem (ou que são merecedores de receber). O ensaio de Mauss é bastante útil em nossa reflexão sobre a benevolência porque reforça o argumento que vimos desenvolvendo a respeito da relação entre a dádiva e o poder. Se as virtudes são qualidades de excelência, seguindo o argumento aristotélico somente poucos podem adquiri-las pelo conhecimento e pelo treino moral. Esses indivíduos raros são por isso mesmo aqueles que exercem o poder, aqueles que pela natureza estão aptos a comandar, seja nos campos de batalha, seja nos seus palácios, na sua família e nos seus territórios. Portanto, somente os homens poderosos podem exercer o poder da benevolência, dispensando aos miseráveis de toda ordem os socorros e as benesses de que necessitam. Em retribuição, recebiam o reconhecimento, a deferência, a obediência.

Tal configuração do poder da dádiva, tão marcado pelo gênero, não relegou as mulheres completamente ao seu isolamento submisso, conforme

8 MAUSS, Marcel. Ensaio sobre a dádiva. In: Paulo: Cosac \& Naif, 2003. 
pudemos ler na Política de Aristóteles. As matronas, grandes senhoras e damas de corte dividiam a virtude da liberalidade ou da caridade no contexto cristão com seus maridos poderosos, como numa emanação do poder marital e senhorial. Há vários registros históricos e memorialísticos em língua latina exaltando as virtudes das matronas, especialmente aquelas que demonstravam suas qualidades de esposa, mãe e senhora, ou seja, dispensadoras dos cuidados com a alimentação, com os doentes, com os desabrigados e com os fracos. Apesar das diferenças hierárquicas entre elas e seus maridos, no que diz respeito ao poder da dádiva ambos se completavam frente aos olhos e às súplicas dos impotentes porque tinham o poder de fazer o bem.

\section{Caridade: virtude moral, virtude cristã}

Se eu falar a língua dos homens e dos anjos e não tiver caridade sou como o metal que soa ou como o sino que tine. E se eu tiver o dom da profecia e conhecer todos os mistérios e quanto se pode saber, e se tiver toda a fé até o ponto de transportar montes e não tiver caridade, não sou nada. E se eu distribuir todos os meus bens ao sustento dos pobres e se entregar o meu corpo para ser queimado, todavia se não tiver caridade nada disto me aproveita. A caridade é paciente, é benigna, a caridade não é invejosa, não obra temerária nem precipitadamente, não se ensoberbece. Não é ambiciosa, não busca seus próprios interesses, não se irrita, não suspeita mal. Não folga com a injustiça, mas com a verdade. Tudo tolera, tudo crê, tudo espera, tudo sofre. [...] Agora, pois, permanecem a fé, a esperança e a caridade, destas três virtudes, porém, a maior delas é a caridade. ${ }^{9}$

Na tradição cristã, fazer o bem assume conotações espirituais mais sutis expressas pela palavra carisma. O ideal de todos os cristãos, desde as primeiras comunidades formadas no Oriente, é imitar Cristo, seguir seu exemplo. Os primeiros divulgadores da fé cristã, os apóstolos, saíram pelas franjas do Império Romano a pregar e organizar as comunidades cristãs num

9 BÍBLIA SAGRADA. Erechim: EDELBRA, 1979. Primeira Epístola de São Paulo aos Coríntios, 13. 
intenso trabalho doutrinador da fé e também da reforma dos costumes. As epístolas do apóstolo Paulo são exemplares desse trabalho e passaram a ser, na Antiguidade Tardia e posteriormente na Igreja Medieval, uma referência doutrinária fundamental para religiosos e laicos.

A etimologia de carisma vem do grego charis e se refere ao dom ou à graça que é concedida por Deus àqueles que o conhecem pela fé. Nas epístolas de Paulo há várias passagens que se referem a este dom supremo espiritual que é a caridade, charitas, amor a Deus. A Primeira Epístola aos Coríntios é um dos textos cristãos mais conhecidos e citados pelos comentadores dos Evangelhos a tratar do carisma de todos os cristãos, que é a caridade. Paulo esclarece que sem o amor (charitas) nenhuma ação tem valor, quanto menos se as suas expressões exteriores servirem a propósitos egoístas, a interesses próprios. A caridade é uma virtude ou um dom/carisma que não tem objetivos imediatos; seu fim é tão somente a manifestação espiritual e exterior da graça de Deus por meio daqueles que a receberam, os cristãos.

A benevolência era, portanto, uma prática esperada dos cristãos não só por expressar uma qualidade moral, como na tradição clássica pagã, mas porque por meio dela se manifestava o amor ao próximo e o amor a Deus; por essa razão, é a principal das virtudes, conforme estabelece o texto paulino. No entanto, nos textos dos apóstolos e nos primeiros textos doutrinários cristãos da Antiguidade Tardia, caridade é mais do que fazer o bem ao outro. Sua amplitude abraça atos, mas principalmente disposições espirituais, como a paz, a misericórdia e o amor. Diferentemente do pensamento clássico, os cristãos não sublinharam tanto a racionalidade dos atos éticos, mas o elo amoroso entre Deus e os homens e entre eles próprios. Assim, no imaginário cristão, fazer o bem é um ato ético porque é justo e correto, no entanto, seu sentido é mais amplo por envolver a dimensão espiritual. $\mathrm{O}$ amor universal é o fim supremo, entendido como a união real dos cristãos com Deus. ${ }^{10}$

Foi Tomás de Aquino quem sistematizou a importância e a centralidade da caridade na vida cristã. Na Suma Teológica, texto dogmático do pensamento teológico cristão medieval, Aquino mostra-se herdeiro dos filósofos clássicos, em especial de Aristóteles, mas sua herança é reelaborada

10 ELIADE, Mircea. The Encyclopedia of Religion. v. 3. New York: Macmillan P. Company; London: Collier Macmillan Publishers, s.d. 
pela fé e pela longa e bem consolidada tradição cristã que o antecede em mais de mil anos. A lista das fontes citadas por Aquino impressiona pela erudição e amplitude. As virtudes ocupam um importante lugar na reflexão tomista, dedicando a segunda parte de seu livro a discorrer sobre a fé, a esperança, a caridade, a prudência e a justiça. ${ }^{11}$

Ao escrever sobre a caridade, uma das três virtudes teologais, Aquino a define como a mãe de todas as virtudes, estabelecendo uma correspondência entre caridade, sabedoria e inteligência, pois a sede da caridade é a vontade, dialogando dessa forma com a Ética de Aristóteles e a tradição patrística. ${ }^{12}$ Interessa-nos mais diretamente a maneira como Aquino trata dos atos de caridade. O ato principal, o móvel da caridade, é o amor. Os atos consequentes são de duas ordens, internos, como a complacência, a paz e a misericórdia, e exteriores, como beneficência, esmolas e correção fraterna.

Para Aquino, a beneficência é a expressão do benfazer pelo outro, ter a vontade de fazê-lo, ou seja, retomando a tradição do pensamento ético, implica a vontade e a escolha do indivíduo em realizar algo em favor de alguém necessitado. A esmola, a dispensa de dinheiro ou de víveres pode ser considerada uma obra primordial dessa vontade de benfazer enquanto a correção fraterna seria uma forma de esmola espiritual na condução moral e espiritual dos desencaminhados.

Certamente que a complexa elaboração teológica sobre a caridade tinha um alcance limitado, afinal, poucos eram capazes de ler na época de Tomás de Aquino e mesmo nos extratos superiores da sociedade medieval tais elaborações foram simplificadas por confessores e preceptores. Nas práticas cotidianas ou em circunstâncias excepcionais, como guerras, fomes e pestes, foram os atos exteriores da caridade que acabaram por prevalecer entre os cristãos. A concepção medieval e mesmo moderna de caridade está profundamente relacionada à noção de dádiva aos pobres e miseráveis.

Associado a esse processo cultural de simplificação e circulação de um conceito com tantas sutilezas como a caridade, é importante lembrar também do problema que representava a riqueza na moralidade cristã medieval. Cristo fora pobre durante a sua vida, assim como os seus seguidores,

11 AQUINO, Tomás de. Suma Teológica. Madrid: Biblioteca de Autores Cristianos, MCMXC (1990).

12 Sigo a interpretação de Luis Lago Alba ao Tratado da Caridade. In: AQUINO, Tomás de. Suma Teológica. Madrid: Biblioteca de Autores Cristianos, MCMXC (1990). p. 203 e 204. 
homens e mulheres humildes. Os textos evangélicos enaltecem a pobreza como valor espiritual, pregando o desapego aos bens materiais, afinal, a verdadeira riqueza não era desse mundo. Como bem expressou Geremek, "a 'economia' da salvação estriba-se na humildade e na abnegação". ${ }^{13}$ Portanto, o valor espiritual da pobreza implicava uma vontade, ou o ideal de pobreza voluntária, muito disseminado com o ascetismo da vida monástica na Europa Ocidental.

Segundo Geremek, a caridade pode ser entendida também como uma forma de ajuste ideológico entre os ideais cristãos e as realidades sociais. Os ricos que não abdicaram das benesses da vida material para entrar na clausura dos mosteiros e conventos encontraram nas manifestações exteriores da caridade uma forma de apaziguar suas consciências e mitigar seus pecados:

"Deus poderia ter feito todos os homens ricos, mas quis que houvesse pobres neste mundo para que os ricos tenham uma oportunidade de redimir os seus pecados": esta máxima, retirada da Vida de Santo Elói, resume bem, numa fórmula tornada clássica, o essencial de tal teoria. A doutrina da caridade deve materializar-se e não tardará a que o faça sob a forma de instituições benemerentes. [...] O dever da caridade passa assim a determinar o comportamento individual dos cristãos na sua vida temporal, ao mesmo tempo que faz da Igreja a gestora da misericórdia social e procuradora dos pobres. ${ }^{14}$

A economia da dádiva nas sociedades cristãs medievais não funcionava de maneira aleatória ou extensiva. A princípio, todos aqueles que necessitassem de proteção e socorro deveriam ser acolhidos pela piedade cristã, mas, desde o início da organização da caridade por intermediação da Igreja ou diretamente na distribuição laica das esmolas por parte dos ricos ou bem situados, foram estabelecidas distinções entre aqueles que seriam merecedores da caridade, os pobres verdadeiros, e aqueles que não seriam dignos de receber esmolas, porque eram desonestos, vagabundos que mendigavam para não trabalhar. De acordo com Geremek, essa distinção

13 GEREMEK, Bronislaw. A piedade e a forca. História da miséria e da caridade na Europa. Lisboa: Terramar, 1995, p. 28.

14 Ibidem, p. 29. 
começa a ser feita e a resultar em efeitos punitivos ainda nos quadros da sociedade medieval e se aperfeiçoa na Modernidade.

A caridade e suas manifestações exteriores, como a esmola e os socorros aos sofredores enunciados pelos Evangelhos, começam a ser associadas cada vez mais às noções de bondade na cultura cristã ocidental. Para um cristão, ser bom continua a ser uma atitude ética, mas o significado é outro, pois reforça os gestos de dádiva e dos cuidados com os miseráveis e desafortunados, como um sinal da extensão do amor a Deus.

$\mathrm{Na}$ cultura cristã ocidental, a dádiva está no centro de uma concepção hierárquica de mundo na qual o poder de dar esmolas e proteger os necessitados é sinal de distinção daqueles que podem dispensar aos necessitados os socorros e auxílios. Na outra ponta da caridade estão os merecedores, os pobres, os doentes, os órfãos, as viúvas, as casas religiosas, os hospitais, enfim, todo um cortejo de necessitados e sofredores que na ética cristã merecem receber as dádivas daqueles que têm o poder da benevolência.

Nesse cenário mental, a bondade devia ser praticada pelos cristãos, independente de quem eles fossem, homens, mulheres, ricos, poderosos, menos ricos, sem poder. Numa visão de mundo profundamente marcada pelo ethos cristão, o gênero não tinha tanta relevância, nem hierarquizava a dádiva e a caridade, que estavam associadas ao poder e ao prestígio das famílias e da religião.

No entanto, o gênero desempenhou um papel importante nas práticas caritativas medievais por meio da organização da vida religiosa feminina e também pela crescente piedade laica entre as mulheres. A vida conventual abria às mulheres acesso à cultura escrita e a um estilo de vida mais independente do poder patriarcal de pais e esposos, integrando outra rede de poder mais difusa de abadessas e bispos, nem sempre muito ciosos e presentes. A pobreza voluntária da vida religiosa representava uma experiência prática da caridade na organização do cotidiano conventual e na devoção. ${ }^{15}$

As mulheres da nobreza, esposas de grandes senhores, também se notabilizaram pela prática da caridade. Representantes do poder de seus maridos, na ausência deles desempenhavam suas funções econômicas,

15 POWER, Eileen. Medieval Women. London: The Folio Society, 2001. 
políticas e sociais. A escritora tardo- medieval Cristina de Pizán orientava que as esposas deveriam ser capazes de substituir seus maridos em tudo e uma dessas atribuições era a caridade, a distribuição de esmolas. No seu livro $A$ cidade das damas, uma defesa das capacidades e das virtudes femininas, ela diz que muitas vezes as mulheres são consideradas avaras, mas que seus cuidados com os excessos de prodigalidade de seus maridos eram demonstração da prudência e não da avareza. Da mesma forma, Cristina diz que a caridade praticada pelas mulheres constitui outra prova de que a avareza não é coisa de mulheres:

\begin{abstract}
A cuántos presos han rescatado, pobres o caballeros en territorio de los sarracenos, a cuántos desheredados han ayudado $\mathrm{y}$ reconfortado todos los días en el mundo, pagando ellas con sus propios bienes! [...] me acuerdo de haber visto unas mujeres muy dignas de elogio por la generosidad y discreción con que daban todo cuanto disponían a un necesitado. [...] Yo sé por qué los hombres insisten tanto hablando de la avaricia femenina, porque por más que se cite la generosidad de Alejandro puedo deciros que esa caridad masculina yo nunca la he visto. ${ }^{16}$
\end{abstract}

Por certo que a caridade e a benevolência são ainda no final da Idade Média virtudes morais extensivas a todos os cristãos, homens e mulheres, mas a escrita de Cristina de Pizán traz algo de novo a esse cenário. Seu livro é uma resposta e ao mesmo tempo a construção de um lugar de defesa para as mulheres, vítimas da maledicência e das injustiças cometidas pelos homens, especialmente pelos escritores antigos e medievais, aos quais Cristina respondia e se opunha. Sua defesa veemente das virtudes femininas e da capacidade intelectual das mulheres antecipa uma longa polêmica constantemente fomentada na cultura europeia em torno da singularidade moral das mulheres. Iniciava-se o debate em torno da solidez e consistência moral das mulheres e nesse debate a discussão sobre a bondade desempenhou importante função na construção dos argumentos. 


\section{Virtudes masculinas, virtudes femininas: a naturalização da bondade}

O quadro de referências morais que apresentamos foi construído e consolidado ao longo de mais de um milênio, precipitando num amálgama da cultura clássica com a cultura cristã. A noção de virtude passou, nesse longuíssimo transcorrer do tempo, por vários ajustes e interpretações, sujeita às circunstâncias e às necessidades de homens e mulheres que, como num espelho, desejavam ver refletidos nessa palavra e no seu significado os valores que aos seus olhos melhor os definiam e os situavam socialmente.

Como vimos, as virtudes intelectuais e morais pareciam ser extensivas a todos os homens e mulheres, embora alguns pensadores clássicos e cristãos considerassem que as virtudes eram modulares, ou seja, adequadas e ajustadas à natureza e ao destino de cada um. Esta concepção modular das virtudes teve maior força e impacto nas relações sociais e nas instituições quando observadas pelas dimensões política e simbólica do gênero. ${ }^{17}$

Virtude é uma palavra que passa a ser invocada e valorizada a partir da cultura humanista renascentista, com um significado mais preciso de gênero. Num contexto de retomada e valorização da cultura clássica, virtude expressa valores associados à masculinidade, ou melhor, a certa concepção de masculinidade, representada pela ação viril pública ou cívica, coragem e sabedoria. A própria etimologia latina (vir) reforçava a ligação entre qualidades e virilidade, conforme cristalizado por Maquiavel em seu livro sobre a racionalidade política, opondo a virtude (masculina) à fortuna (feminina) com conotações explícitas de poder sexual. ${ }^{18}$

17 Neste artigo o enfoque central é o gênero, mas a frase poderia ser complementada pela dimensão de classe, afinal, boa parte dos argumentos medievais e modernos sobre a hierarquia social e sua imutabilidade se sustentava na distribuição desigual, porque natural, das qualidades morais. Dessa forma, seria absolutamente plausível e racional que os poderosos, ricos e livres mandassem e mantivessem sob o seu poder os pobres, os escravos e os servos, pois estes não detinham as qualidades morais suficientes para decidir e comandar. A escassez das virtudes morais entre os inferiores justificava a desigualdade e a manutenção da ordem social hierárquica.

18 MAQUIAVEL, Nicolau. O Príncipe. São Paulo: Editora Moraes, s.d. Lembro-me da famosa passagem do Capítulo XXV sobre a relação entre a virtude e o destino: "Estou convicto que o impetuoso encontra mais facilmente o caminho do sucesso do que o cauteloso, porque a sorte é mulher e só se submete quando é contrariada e surrada. E, sendo mulher, se aproxima mais dos jovens que são menos cautelosos, têm mais ardor e a envolvem com mais audácia”. (p. 122) 
Portanto, conforme nos aproximamos do pensamento político laico do alvorecer moderno, notamos não só a persistência da teoria aristotélica da modulação das virtudes, mas igualmente a crescente distinção entre tipos de virtudes, uma tipologia construída a partir de referências sociais e de gênero principalmente. Dessa forma, começa-se a ler nos escritos tardo-medievais e do início da Época Moderna expressões como virtude monárquica ou principesca, virtude cavalheiresca, virtude cívica, sem contradizer as virtudes cristãs e morais, muito bem conhecidas e pretensamente praticadas pelos homens excelentes.

Estas virtudes são todas masculinas porque requerem ações pública e política, vetadas para as mulheres, como também qualidades físicas (força, destreza, agilidade), morais e intelectuais que dificilmente as mulheres da época de Maquiavel poderiam desenvolver. Não porque elas fossem incapazes, mas porque, como bem havia declarado Cristina de Pizán, sua educação era extremamente limitada e os elos do poder patriarcal as restringiam à família, à piedade devota e à maternidade.

Cristina de Pizán sabia do que estava falando ao evocar as qualidades femininas para defender a excelência moral das mulheres, ou seja, sua estratégia narrativa visava empoderá-las lançando mão de parte do mesmo arsenal utilizado pelos homens: cultura, erudição, virtudes. No entanto, Pizán, como tantas outras escritoras depois dela e tantos homens aliados à causa das mulheres, temia a confusão das fronteiras de gênero e os custos sociais e morais que tal embaralhamento poderia resultar para a dignidade das mulheres. Por essa razão, ela e suas descendentes culturais constroem uma cidadela moral para as mulheres com a finalidade de valorizá-las, na qual só adentram as mulheres excelentes, unindo imaginariamente as virtuosas mulheres do passado e do presente, históricas e mitológicas, reais e ficcionais.

Um dos pilares fundamentais desse discurso moral favorável às mulheres é a virtude, entendida como específica das mulheres, ou seja, a virtude feminina. Nota-se que, da mesma forma que noções masculinas de virtude passaram a ser comumente usadas nos textos modernos, virtudes femininas são evocadas para ressaltar certas qualidades, como a castidade, a modéstia e a caridade. Não estamos no terreno da unanimidade quando nos reportamos aos diferentes tipos de textos escritos sobre as mulheres no começo da Modernidade, pois não se pode esquecer a persistência das 
imagens negativas, satíricas e mesmo misóginas de tão longa duração. ${ }^{19}$ Para os detratores das mulheres, nada de bom havia naquelas criaturas feitas da costela torta de Adão. Numa sólida tradição misógina que lança suas raízes nos textos clássicos satíricos emergem as imagens da mulher sedutora, luxuriosa, intrigante, sibilina, perigosa e não confiável, portanto.

Operando com contraimagens, o discurso moderno em favor das mulheres, que começa com Pizán e se fortalece entre os séculos XVI e XVIII, enaltece principalmente as virtudes femininas da castidade e da caridade. A castidade era uma qualidade importante a se preservar e defender, pois estabelecia uma forte diferença moral entre as mulheres e os homens, que na sua grande maioria, ricos ou pobres, senhores ou subalternos, pareciam ser mais descontrolados, sendo a imagem do homem violador bastante presente nos contos satíricos e escritos moralistas. Uma mulher casta, mesmo casada, remetia à ideia positiva da remissão da falta original pela mediação da Virgem Mãe. A mariolatria já tinha lançado suas raízes desde meados do século XII e a Virgem Maria parecia ser uma forte aliada na batalha dos discursos sobre as capacidades e qualidades femininas. ${ }^{20}$

Outra qualidade ressaltada e que passará a ser cada vez mais associada à feminilidade é a caridade, par adequado à castidade feminina. Com ressonâncias clássicas e cristãs, essa virtude enfeixava valores morais e espirituais bastante enaltecidos, principalmente pelas próprias mulheres que escreviam. Uma boa mulher, uma mulher de valor seria, portanto, aquela que demonstrasse por seus atos o autocontrole e o comedimento da castidade; e a piedade, o devotamento àqueles que sofriam e a dedicação desinteressada pelos pobres e desafortunados da caridade. Dessa forma, mulheres ricas e cultas (da nobreza e da burguesia mercantil) podiam ser comparadas positivamente aos homens por sua excelência. A caridade era a virtude que mais as aproximava dos homens em dois sentidos. O homem excelente praticava a virtude cristã da caridade, mas a virtude cívica ou política também exigia os mesmos atributos de abnegação e dedicação desinteressada, só que pelo bem comum, enquanto o altruísmo feminino

19 É importante destacar que um mesmo autor poderia numa mesma obra realizar um movimento pendular entre imagens negativas e positivas das mulheres. Este é o caso de Boccaccio e seu livro Mulieribus claris, publicado em 1374, apresentando 106 biografias de mulheres históricas e mitológicas, ilustres pelo bem e pelo mal que, segundo Boccaccio, teriam elas cometido.

20 WARNER, Marina. Alone of all her sex. The myth and the cult of the Virgin Mary. New York: Vintage Books, 1983. 
se voltava para um grupo específico de pessoas, como numa extensão da família, e não a cidade ou o reino.

Esses discursos se inserem na tradição clássica e cristã, embora se observe certa alteração dos conceitos de virtude pela valoração de gênero cada vez mais acentuada nos escritos morais e religiosos da modernidade. A reflexão moral na modernidade vai sofrer uma inflexão motivada pela Reforma Protestante, pela problematização filosófico-científica do Sujeito e da Natureza e pelo deslocamento favorável às sensibilidades e aos sentimentos conduzido pela escrita dos romances. Nesse novo contexto, situado entre os séculos XVII e XVIII, o debate em torno das virtudes femininas e masculinas toma vulto e ocupa um lugar de destaque na cultura e nas sociabilidades modernas.

As diversas denominações religiosas cristãs originárias da Reforma Protestante sublinhavam que as condutas dos cristãos deveriam ser pautadas pelas virtudes cristãs, voltando com severidade ao Evangelho, particularmente às epístolas de São Paulo. Virtudes são manifestações espirituais e exteriores da graça de Deus, assim, os autores religiosos protestantes valorizavam a caridade como expressão da benevolência desinteressada e alguns deles concediam que as mulheres podiam ser mais receptivas à graça devido a sua sensibilidade e às emoções mais exaltadas do que os homens. Na Europa e nas colônias americanas, os pastores escreveram vários sermões exortando as mulheres a uma vida modesta, industriosa, obediente e piedosa. ${ }^{21}$

Por outro lado, as mulheres protestantes tinham uma liberdade maior que as católicas na relação que estabeleciam com os escritos religiosos, especialmente na leitura da Bíblia feita em família ou mesmo solitária. Motivo de preocupação desde a época dos reformadores históricos Lutero e Calvino, a leitura da Bíblia sem intermediação de uma autoridade pastoral poderia dar abrigo a interpretações mais livres e heterodoxas. Não se tem muitas informações de como mulheres comuns liam a Bíblia, mas livros de piedade de natureza autobiográfica escritos por mulheres protestantes desde o século XVII revelam como algumas delas faziam interpretações da vida de Jesus ou das tantas mulheres bíblicas de maneira inspiradora para suas próprias vidas e principalmente para se fortalecer espiritual e moralmente. ${ }^{22}$

21 BLOCH, Ruth. The gendered meanings of virtue in Revolutionary America. Signs, v. 13, n. 1, p. 37-58, Autumn, 1987.

22 MOTHERSOLE, Brenda. Female philanthropy and women novelists of 1840-1870. Thesis (Doctor of Philosophy) - Faculty of Education and Design, Brunel University, 1989. 
As reflexões filosóficas modernas sobre o sujeito também trataram das virtudes. Seguindo as formulações clássicas sobre a moral, os filósofos racionalistas dos séculos XVII e XVIII consideravam as virtudes fundamentais para a educação do homem. Os empiristas ingleses e os sensistas escoceses do século XVII concordavam que as virtudes deviam ser cultivadas pela educação intelectual e moral desde a infância, mas esse era o caminho reservado para os meninos fundamentalmente. A relação entre a filosofia e a pedagogia na modernidade visava à formação de um sujeito masculino. Alguns mais esclarecidos, como John Locke, até concordavam que as meninas deviam ter uma educação mais esmerada para além da alfabetização, da música e dos trabalhos de agulha, mas a educação das meninas era limitada ao que então se considerava a natureza feminina, expressão cada vez mais corrente nos discursos filosóficos e da nascente ciência. Portanto, nesses discursos as virtudes se alinhavam ao gênero, separadas pela masculinidade e pela feminilidade. A educação moral e religiosa dos meninos deveria cultivar as virtudes de um homem público, cuja conduta estivesse de acordo com as funções políticas, sociais e econômicas. A educação das meninas, por sua vez, deveria cultivar as virtudes femininas, como a castidade, a modéstia e a caridade, qualidades exigidas da mulher cuja conduta estivesse de acordo com as suas funções privadas de esposa, mãe e caridosa dispensadora de esmolas e cuidados com os pobres. ${ }^{23}$

Desde meados do século XVII, um novo paradigma estético se configura na cultura literária inicialmente, representado pelo romance. Terreno dominado pelas mulheres, o romance era um gênero literário bastante diferente das epopeias, com sua linguagem poética e suas narrativas sobre heróis e virtudes masculinas. O romance contava histórias de amor tendo como antepassado o roman medieval sobre casais de amantes cujo amor geralmente afrontava a ordem conjugal, terminando quase sempre num destino trágico de morte amorosa.

Esse paradigma deslocava o eixo moral do heroísmo masculino das epopeias ao criar um sólido eixo moral dos sentimentos e das virtudes femininas. As heroínas dos romances ocupam a cena principal. Os enredos são delas, de seus percursos como sujeitos dotados de razão certamente, mas também e na mesma medida de sentimentos e principalmente de virtudes, 
que, aliadas da razão, as impediam de enveredar pelos caminhos tortuosos do desregramento, dos vícios, da perdição. ${ }^{24}$

Em conjunto, essa nebulosa discursiva moderna contribuiu para a configuração das subjetividades femininas e de sua imagem emocional. Homens e mulheres romancistas, mas também a escrita do ensaio filosófico-moral muito praticada pelas mulheres cultas nos séculos XVII e XVIII, foram aos poucos construindo uma imagem feminina indissociável da noção de virtude. Virtude foi uma palavra que naquele contexto significava intensidade emocional, sensibilidade, piedade, amor e bondade. Mulheres de virtude deviam expressar todas essas qualidades, mas o que se observa, especialmente a partir da segunda metade do século XVIII, é a prevalência da bondade sobre as outras qualidades. ${ }^{25}$

Isto se deve em boa medida devido a todo um repensar sobre a constituição moral dos homens. Nas religiões católica e protestante e na filosofia moderna preponderava uma antropologia pessimista, devido ao pecado original ou à predominância das paixões deletérias que exigiam que a ordem política se estabelecesse para colocar um freio às ambições desmedidas, ao orgulho e à violência. ${ }^{26} \mathrm{~A}$ maldade era intrínseca ao homem e somente pela religião e pelo poder instituído ele poderia se transformar e ser útil à sociedade. Essa visão pessimista começou a ser questionada ainda no século XVII por moralistas e também por mulheres escritoras ao não sublinharem o determinismo das formulações religiosas e racionalistas, mas sim a ideia bastante antiga do livre arbítrio e de que o bem era uma disposição tão presente na natureza humana quanto o mal.

Tal mudança de enfoque se deve a outra questão, que é a visão mais positiva e benéfica da Natureza, essa dimensão ou conceito fundamental para a formulação do pensamento moderno. Desde o Renascimento a Natureza foi perdendo a aura de mistério ou de sacralidade que por muito tempo a

24 Sobre os romances e as escritoras do século XVII e a problematização moral, ver ZECHLINSKI, Beatriz Polidori. Três autoras francesas e a cultura escrita no século XVII: gênero e sociabilidades. Tese (Doutorado) - Programa de Pós-Graduação em História, Universidade Federal do Paraná. Curitiba, 2012.

25 Da ampla produção literária e ensaística de autoria feminina destaco tão somente como exemplos GRAFFIGNY, Madame de. Lettres d'une Perunienne. Paris: Flammarion: 2005, publicado em 1747; LAMBERT, Madame de. Avis d'une mère à sa fille. Paris: Éditions Payot \& Rivages, 2007, escrito entre 1688 e 1692.

26 O texto moderno canônico sobre a antropologia pessimista é de HOBBES, Thomas. Leviatã. São Paulo: Ícone, 2000. O livro foi publicado em 1650. 
envolveu, configurando-se como um lugar de origem e de moralidade, essencialmente bom porque sem desordem, sem violência. $\mathrm{O}$ discurso naturalista dos filósofos racionalistas e empiristas dos séculos XVII e XVIII passou a sublinhar que o bem era também um estado natural e os homens enquanto criaturas naturais também traziam essa potência para o bem, precisando tão somente ter as condições propícias dadas pela cultura para se manifestar em obras úteis e boas.

Apesar do ceticismo corrente no pensamento das Luzes quanto a esta questão da bondade humana, se avolumam ao longo do século XVIII os escritos a respeito da bondade natural ou de sentimentos morais naturais. Pensadores tão diferentes como Adam Smith e Jean Jacques Rousseau compartilhavam dessas ideias. É nesse cenário mais otimista que toma corpo a discussão em torno das virtudes femininas como expressão de uma natureza propiciadora. Inspirada pela religião, a maioria das mulheres escritoras do século XVIII ressaltava que, devido à natureza feminina ser mais propícia aos cuidados e à sensibilidade suscitada por sentidos mais aguçados, as mulheres estavam mais fadadas à bondade e às suas manifestações por meio de ações benemerentes. Outras, menos influenciadas pela religião e leitoras dos ensaios filosóficos e dos romances, se lançaram à escrita elas também para enaltecer as qualidades naturais da moralidade feminina, vendo nelas uma justificativa para a mudança dos costumes em relação às mulheres, especialmente no que dizia respeito à educação feminina. Também perceberam que a bondade abria oportunidades de ação para as mulheres por meio de uma benevolência ativa, ou seja, o envolvimento com obras de caridade, não só como dispensadoras de esmolas, mas orientando e organizando escolas para meninas pobres e órfãs, hospitais, escolas dominicais, associações de apoio a causas nacionais, como foi o caso pioneiro das mulheres americanas que criaram organizações para arrecadar fundos para a revolução americana. ${ }^{27}$

A naturalização das virtudes femininas encontrou em Rousseau um de seus mais notórios divulgadores e defensores. No famoso capítulo final do livro Emílio, publicado em 1762, Rousseau trata da educação e da natureza da companheira do novo homem. Sofia é a representação de uma natureza feminina completamente sexual (essa é a sua diferença principal em relação

27 Duas dessas organizações desempenharam esse papel que articula a virtude feminina com a virtude pública no contexto da revolução americana, Daughters of Liberty e Ladies Association. Cf. BLOCH, Ruth. Op. cit. 
ao homem), estável e imutável. Rousseau imagina em Sofia a mulher natural, boa, sensível, forte, terreno fértil pronto para receber a intervenção masculina e frutificar como mãe. No entanto, a mulher natural não é somente passiva e submissa ao homem. Ela tem o seu poder. Ela domina o homem pelo amor e pelas virtudes. É interessante notar como Emílio vai sendo magnetizado pela simplicidade e pela força moral de Sofia, ficando completamente apaixonado e com ela se casando. Sofia tem poder emocional, mas ela não o usa para seduzir com propósitos egoístas ou levianos. Não, a natureza de Sofia não conhece esses vícios. Ela é profundamente boa, como tantas heroínas de romances finisseculares e as do século XIX foram. Sofia e suas irmãs românticas reais ou ficcionais são boas sempre, com seus irmãozinhos, com os pais, com os pobres que precisam de sua ajuda bondosa, com seus amantes estouvados, que nem sempre sabem como delas se aproximar.

Rousseau recebeu críticas das mulheres de sua época, algumas suas amigas, que não concordavam com a imagem excessivamente passiva e doméstica de Sofia. Queriam mais, tinham ambições intelectuais e sociais para si e para as outras mulheres. No entanto, nenhuma delas discordou da ideia de uma natureza feminina boa, pelo menos não com a radicalidade de Mary Wollstonecraft, embora ela também defendesse ardorosamente uma imagem positiva das mulheres em grande parte sustentada nas virtudes morais e naturais. ${ }^{28}$

A naturalização da bondade não deveu sua fortuna crítica somente às elaborações filosóficas e literárias do século XVIII. Em boa medida, as próprias mulheres contribuíram para a construção da imagem da mulher benevolente e da associação entre bondade e feminilidade porque, desde meados do século XVIII e especialmente no século XIX, um número crescente delas passou a se envolver intensamente com as ações de benemerência, caritativas e filantrópicas. A palavra filantropia passou a ser de uso mais corrente nos séculos XVIII e XIX para dar conta de diferentes ações benemerentes, não necessariamente motivadas pelo zelo religioso, mas fundamentalmente ligadas àqueles valores sobre a compaixão e a bondade naturais, extensivos a todos os homens e mulheres racionais e sensíveis.

28 Sobre Rousseau e as críticas formuladas pelas mulheres de sua época, ver REIS, Anadir dos Santos. Mary Wollstonecraft e a reflexão sobre os limites do pensamento liberal e democrático a respeito dos direitos femininos. 1759-1797. Dissertação (Mestrado) - Programa de Pós-Graduação em História, Universidade Federal do Paraná. Curitiba, 2010. 
Portanto, a filantropia é uma ação mais ampla em seu escopo benevolente, abrangendo desde as antigas práticas caritativas individuais, até a defesa das artes, da cultura, dos legados históricos e arquitetônicos e também dos animais. A caridade geralmente era um ato individual, enquanto a filantropia passou a ser no século XIX cada vez mais associada a grupos e ações coletivas, como se observa no movimento abolicionista e nos movimentos de reforma social do século XIX, embora muitas pessoas, homens e mulheres ricos, tenham se notabilizado como grandes filantropos sem terem se envolvido em movimentos sociais, praticando a filantropia individual.

O envolvimento crescente com a filantropia das mulheres europeias e americanas das classes mais favorecidas se deveu à valorização das virtudes femininas, mas ao mesmo tempo essa valorização se deu pela ação das mulheres, porque muitas delas perceberam que, frente às limitadas oportunidades de expressão e de participação social, a filantropia as destacava e abria possibilidades de participar do mundo público. O século XIX pode ser considerado como a época da filantropia feminina, quando se cristaliza a associação entre bondade e feminilidade. Esse processo não se deu sem contestações e críticas, pois muitos homens contemporâneos viam com temor a perambulação das mulheres de elite por lugares moralmente suspeitos, como os bairros populares, as prisões, as workhouses, os manicômios, as ruas dos bordéis. No entanto, o processo deslanchado não tinha como ser barrado, pois em todas as classes sociais as mulheres queriam participar ou eram instadas a se envolver com a filantropia. $\mathrm{O}$ trabalho filantrópico, como passou a ser também chamado, embora fosse completamente voluntário, permitiu a muitas mulheres se envolver com outras dimensões da benemerência que as levaram aos gabinetes dos políticos, muitos deles de suas relações familiares ou de amizade, inserindo-se na esfera das reformas sociais e dos debates políticos em torno das questões sociais candentes no século XIX, em especial a partir das décadas de 1830 e $1840 .{ }^{29}$

Há inúmeros registros desse processo da feminilização da bondade pela inserção de milhares de mulheres na filantropia. ${ }^{30}$ Trazemos para esse

29 MOTHERSOLE, Brenda. Op. cit.

30 As pesquisas pioneiras sobre esse processo são de PROCHASKA, E. Frank. Women and philanthropy in Nineteenth-Century England. Oxford: Clarendon, 1980; McCARTHY, Kathleen D. (Ed.). Lady bountiful revisited. Women, philanthropy and power. New Brunswick/London: Rutgers University Press, 1990; ELLIOT, Dorice Williams. The angel out of the house. Philanthropy and gender in NineteenthCentury England. Charlottesville/London: University Press of Virginia, 2002. 
artigo um dos mais interessantes, que é o livro publicado em 1893 por uma mulher muito rica, talvez uma das mulheres mais ricas do Reino Unido, a baronesa Angela Burdett-Coutts. ${ }^{31}$

O livro é uma coletânea de capítulos escritos por várias mulheres envolvidas com a filantropia e foi encomendado pela Princesa Helena de Schleswigg-Holstein, filha da Rainha Vitória e notória filantropa. Trata-se do relatório do trabalho filantrópico desenvolvido pelas mulheres inglesas por meio de diferentes organizações nacionais, missionárias e religiosas e de instituições filantrópicas dos mais diversos tipos, que foram selecionadas e organizadas, inclusive com ilustrações expostas no Pavilhão das Mulheres na Exposição Universal de Chicago em 1893. Angela foi convidada pela Comissão Real para integrar o Comitê de Senhoras, presidido pela Princesa, e por esse motivo organizou o relatório.

O interesse nesse registro reside no fato de que ela e suas colaboradoras fizeram um verdadeiro trabalho de pesquisa sobre a filantropia no Reino Unido. O relatório consta de duas partes. Uma é impressa e foi escrita pelas filantropas; a outra tem cinco volumes e contém todos os questionários e o material que foi enviado pelas lideranças religiosas e femininas das organizações filantrópicas da Inglaterra, Escócia, Irlanda e das colônias do império britânico, abrangendo um período de sessenta anos. Trata-se, portanto, de um extenso e rico material da história da assistência filantrópica, mas o que nos interessa é a interpretação que a baronesa faz desse longo processo de envolvimento das mulheres com a bondade.

Ela escolhe fazer uma abordagem histórica. Começa dizendo que foram grandes e profundas as mudanças nas condições de vida e de trabalho das pessoas comuns na Inglaterra devido à Revolução Industrial. Essa situação exigiu novas formas de ação para melhorar a vida dos pobres, pois a baronesa reconhecia que as transformações tecnológicas e o livre comércio trouxeram riqueza e progresso, mas também um cortejo de mazelas com o crescimento da pobreza. No entanto, ela faz questão de lembrar que a ação benemerente começou muito antes da Revolução Industrial. O mesmo sentimento que animava as mulheres inglesas de fins do século XIX também esteve presente entre as suas antepassadas da época da Rainha Elizabeth.

31 BURDETT-COUTTS, Angela. Woman's Mission. A series of Congress Papers on the Philanthropic Work of Women by eminent writers. New York: Sampson Low, Marston \& Company, 1893. Disponível em: <www.archive.org/details/womansmissionser00burdiala>. 
Para a baronesa, não se podia esquecer o bem que foi feito no passado e muito do que era realizado no presente seria impossível sem a experiência herdada pela filantropia praticada nos grandes domínios senhoriais. O presente deveria ser a continuidade de um processo benevolente. Complementa dizendo que havia milhares de pequenos centros de benevolência cujas informações não estavam registradas em lugar algum a não ser nos registros dos anjos. Apesar de todas as transformações operadas no mundo rural e senhorial inglês, em cada paróquia havia boas mulheres trabalhando juntas pelos pobres e necessitados sob o nome de Associação ou Sociedade.

$\mathrm{O}$ enaltecimento do trabalho filantrópico não podia, segundo a baronesa, ser desvinculado de uma tradição benevolente feminina: "O bom trabalho que as mulheres fazem associadas se origina daquele que foi realizado nas famílias de forma tranquila. Raramente exibido como ação conjunta, piedade e caridade são agora combinadas na bela palavra Filantropia, chegando ao presente pelo belo e dourado caminho." 32

Angela Burdett-Coutts e tantas outras mulheres de sua época consideravam que a filantropia era um trabalho e um movimento do coração porque impulsionada pelas virtudes e pela sensibilidade. A bondade passou a ser a palavra mais usada para enfeixar todas as ações e movimentos liderados por mulheres em favor dos necessitados e de todas as causas humanitárias, a começar pelo abolicionismo.

Ao término do século XIX, a bondade era uma palavra não só feminina do ponto de vista gramatical. Bondade era a expressão das mulheres, $\mathrm{o}$ que melhor as definia no plano do imaginário social e das sensibilidades. A feminilização da bondade esteve na origem não só da limitação das mulheres a certos rituais sociais da benevolência e da reprodução da dominação de classe e de gênero. É preciso ampliar nossa compreensão das suas múltiplas dimensões e significados, sendo também uma experiência que está na origem da inserção de muitas mulheres em movimentos sociais e políticos, como o feminismo, e na organização das profissões femininas.

Recebido em outubro de 2013. Aprovado em novembro de 2013. 